\title{
The Study of Subsurface Land Drainage Optimal Design Model
}

\author{
Ahmad Bakour $\mathbb{D}^{1},{ }^{1}$ Zhanyu Zhang $\mathbb{D},{ }^{1}$ Chengxin Zheng $\mathbb{D},{ }^{2}$ Mohamed A. ALsakran $\left(\mathbb{D},{ }^{3}\right.$ \\ and Mohamad Bakir iD ${ }^{4}$ \\ ${ }^{1}$ College of Agricultural Science and Engineering, Hohai University, Nanjing 210098, China \\ ${ }^{2}$ College of Water Conservancy and Hydropower Engineering, Hohai University, Nanjing 210098, China \\ ${ }^{3}$ College of Civil and Transportation Engineering, Hohai University, Nanjing 210098, China \\ ${ }^{4}$ College of Hydrology and Water Resources, Hohai University, Nanjing 210098, China
}

Correspondence should be addressed to Zhanyu Zhang; zhanyu@hhu.edu.cn

Received 29 September 2020; Accepted 4 June 2021; Published 16 June 2021

Academic Editor: Tianwei Zhang

Copyright $\odot 2021$ Ahmad Bakour et al. This is an open access article distributed under the Creative Commons Attribution License, which permits unrestricted use, distribution, and reproduction in any medium, provided the original work is properly cited.

\begin{abstract}
This paper focused on choosing the best design of subsurface land drainage systems in semiarid areas. The study presented three different soil layers with different hydraulic conductivity and permeability, all layers are below the drain level, and the permeability is increasing with depth. A mathematical model was formulated for the horizontal and vertical drainage optimal design. The result was a nonlinear optimization problem with nonlinear constraints, which required numerical methods for its solution. The purpose of the mathematical model is to find the best values of pipes and tubewells spacing, groundwater table drawdown, and pumps operating hours which leads to a minimum total cost of the subsurface drainage design. A computer code was developed in MATLAB environment and applied to the case study. Results show that the vertical drainage was economically better for the case study drainage network design. And the main factor affecting the mathematical model for both pipe and well drainage was the distance between pipes and tubewells. In addition, considering the lifespan of vertical drainage project, the optimal design involves the minimum possible duration of pumping stations. It is hoped that the proposed optimal mathematical model will present a design methodology by which the costs of all alternative designs can be compared so that the least-cost design is selected.
\end{abstract}

\section{Introduction}

Subsurface drainage is widely used worldwide to remove excess water found below the earth's surface [1]. While surface drainage removes excess water from the soil surface before it enters the crop root zone, subsurface drainage decreases the groundwater level and provides a better environment for the crop growth [2]. Agricultural lands affected by salinity and high water levels generally require subsurface drainage [3]. Two methods of subsurface drainage are commonly used which are horizontal pipe drainage and vertical well drainage. Subsurface pipe drainage is a group of lateral pipes spread below the ground surface with specific depths, diameters, and spacing between them and connected with collector pipes that draw the surplus water out of the study area. Vertical drainage is a group of vertical wells, with specific diameters, depths, and spacing between them. These wells are equipped with pumps that withdraw water, so the water level will decrease in the surrounding area. Land drainage helps to achieve water balance in the soil, prevent its salinization, and create favourable conditions for plant growth. Around the world, agricultural drainage plays a significant role in protecting investments in irrigation projects and agricultural production. It helps also in preserving soil resources and food production, by improving land productivity and crop yields, especially in poorly drained soils [4]. Most studies that involve subsurface drainage were about the design of the drainage network, and the task is to find the best design or the optimal design. The most important strategy in designing the subsurface drainage is choosing proper values for the spacing and depth of drains to minimize the total cost [5]. And a lot of researchers have studied the cost analysis of subsurface drainage systems for different types [6-11]. Cimorelli et al. [12] have worked on the surface drainage network optimal design and introduced a novel procedure 
for the best surface drainage network design. A methodology was presented by Chahar and Vadodaria [8], for determining the optimal spacing of ditches fully penetrating into an isotropic and homogeneous porous medium over an impervious layer. Another methodology was introduced by Moradi-Jalal et al. [13], for the optimal operation and design of pumping stations based on solving a nonlinear large-scale programming problem. And a new management model was presented by Moradi-Jalal et al. [14], for the optimal operation and design of water distribution systems. An objective function was constructed by Sharma and Swamee [15], for the cost structure of a pipe network system. The optimization model described by Bennett and Mays [16] was based upon dynamic programming for nonserial systems that determines the minimum cost of a drainage channel system and the detention for a watershed. A nonlinear square fitting routine was used by Wall and Miller [17] to determine the effective values of conductivity and moisture characteristics of the model of soil water drainage. And a simulation model of the optimal drainage network was presented by Howard [18], in which channels shift to minimize the total stream power within the network.

This paper presents a novel strategy for the best design of subsurface horizontal and vertical drainage in an area of different saturated soil layers with different hydraulic conductivity and permeability, and the permeability is increasing with depth. With the use of modern optimization algorithms, we can find the suitable values of groundwater table drawdown and pipes/tubewells spacing that lead to the minimum cost of the total subsurface drainage system.

\section{Methodology}

The least-cost design is that satisfying all design constraints with the minimum total cost. The objective function for pipe and well drainage was determined by considering all cost components that affect the drainage network design. Then constraints were formulated depending on the hydraulic study of the study area. The result was a nonlinear objective function with nonlinear constraints. A survey of modern optimization algorisms was conducted to find the one suitable for the solution of the formulated optimization problem. It was found that the interior-point optimization algorithm was adapted to the problem and produced satisfactory results. Two computer codes for both horizontal and vertical subsurface drainage were developed in MAT$\mathrm{LAB}$ environment in order to derive the optimal solution for both types of drainage systems. The solutions then were compered to know how the lifespan and type of the project will affect the total cost of the network design.

\section{Pipe Drainage Costs}

The major cost components of pipe drainage system are drainage materials, installation, and operation and maintenance.

3.1. Drainage Materials. The costs of drainage materials and drainage pipe installation work and structures are major components of the total cost of a pipe drain project. Drainage materials include collector and lateral pipes, filters, pump set and pump house, outlet structures and manholes, and outlet pitching.

Collector and lateral pipes: the collector pipes have a transmission function to carry water to the outlet under the gravitational flow, so the UPVC (unplasticized poly vinyl chloride) corrugated nonperforated pipe is used for the collectors. The pipe diameter of the collectors is chosen depending on the expected flow. Single Wall Perforated Flexible Corrugated UPVC Pipes (outer diameters of 80-355 $\mathrm{mm}$ ) are widely used for lateral pipes.

Artificial filters/envelopes: the filter or envelope material around the pipes plays an important role in preventing the fine particles of the soil from entering into the pipes with the flow. Nowadays, it is preferred to use artificial filters rather than gravel filters. The artificial filters are cheaper in cost, of better quality, and easier to handle and transport than gravel filters. For medium and light soil, it is preferred to use nonwoven polypropylene fibers with a thickness of more than $2.5 \mathrm{~mm}$ and an opening size of more than 300 microns, and a needle punched geotextile nonwoven fabrics are used for heavy soil. Perforated pipes precoated with industrial filter are more preferred than locally coated pipes for quality installation.

Pump set and structures: pump set and structure consists of diesel pump set and pump house, manholes (junction box), and outlet structures. Other cross drain structures may also be required in larger projects but these are avoided for simplicity. The outlet structure and manholes are precast Reinforced Cement Concrete (RCC) pipes of different lengths and diameters depending on the site conditions. In the case of pump outlets, $900 \mathrm{~mm}$ diameter manholes and $1200 \mathrm{~mm}$ outlet structures are used, where $900 \mathrm{~mm}$ diameter manholes are used in the gravity outlets. The bottom edge of the RCC pipe for outlet structures and manholes is closed by fixed plate at the bottom. Plastic coated iron bars are provided in the walls of outlet structures and manholes to help in inspection and cleaning. In the case of gravity outlets, instead of RCC pipes, plastic manholes and outlet pipes have recently been used. Plastic manholes and outlet pipes are relatively expensive, but they are easy to carry, handle, and install at the project sites [19]. A small stone structure is constructed at the outlet to protect the pipe end from collapsing under the conditions of gravity outlet. A rodent guard is provided to prevent the pipes from getting stuck and damaged by rodents that may enter the lateral pipes.

3.2. Installation. Installing the drainage system is the function of the installation unit according to the specifications and design. Supervisors must specify that the installation (including drainage equipment) is carried out strictly in accordance with specifications and design. Various drainage machines such as hydraulic excavators, tractor-mounted trenchers, self-propelled trenchers with laser automatic control, and self-propelled machines with $L$ or $V$ plough and laser control are used to install collector and lateral pipes $[20,21]$. Currently, laser control self-propelled 
trenchers are used in large-scale quality of subsurface drainage pipes installations. Other auxiliary machineries like bulldozers, excavators, tractors with trailers, backhoe, etc. are also used for the movement of manpower, drainage materials, and installation of outlets and manholes. Individual farmers can use tractor mounted trencher in small areas (1-5 ha) to install subsurface drainage pipes. In such cases, it may be desirable to use a laser control device with a tractor-mounted trencher to achieve suitable slope for collector and lateral pipes.

3.3. Operation and Maintenance. The popular belief that subsurface drainage does not require any maintenance and operation is untenable. In the case of pump outlets, pump operation is required for at least the first few years of installation. The maintenance of subsurface drainage systems mainly involves removing sediment from outlets, manholes, and pipes, also repairing or replacing the damaged outlets, manholes, and pipes [20]. In controlled drainage systems, operations may also include closing and opening gates to reuse drained water to irrigate crops.

3.4. Pipe Drainage Cost Equation. The most cost components that affect the subsurface pipe drainage design can be determined according to the total costs as shown in the following relationship:

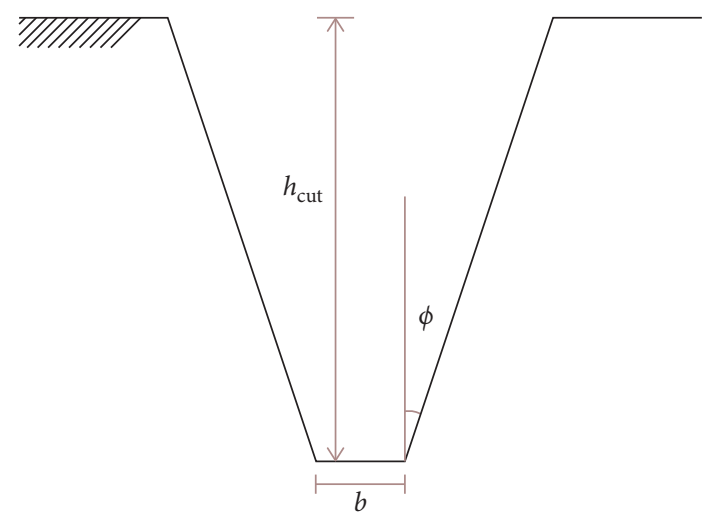

Figure 1: Cross section of excavation.

$$
z_{i}=W_{i}+\frac{\left(1+E_{0}\right)^{D}-1}{E_{0}\left(1+E_{0}\right)^{D}} * U_{i},
$$

where $i$ is the number of the choice $(-), z_{i}$ is the total costs for the choice $i(\$), E_{0}$ is the interest rate (\%), $W_{i}$ is the construction costs for the choice $i(\$), D$ is the lifespan of the drainage project (years), and $U_{i}$ is the annual investment costs for the choice $i$ (\$/year).

The construction costs are calculated by using the following equation:

$$
W_{i}=\sum l_{i} *\left(A_{\text {cut }} * C_{\text {cut }}+0.5 * I C_{\text {cut }} * A_{\text {cut }} * h_{\text {cut }}+C_{p}\right)+n_{m} * h_{\text {cut }} * C_{m}
$$

where $\sum l_{i}$ is the total length of all drainage pipes $(\mathrm{m}), A_{\text {cut }}$ is the cross-sectional area of excavation $\left(\mathrm{m}^{2}\right), C_{\text {cut }}$ is the unit cost of excavation $\left(\$ / \mathrm{m}^{3}\right), I C_{\text {cut }}$ is the increase in unit cost of earthwork per unit depth of excavation $\left(\$ / \mathrm{m}^{3} / \mathrm{m}\right), h_{\text {cut }}$ is the depth of excavated ditch $(\mathrm{m}), C_{p}$ is the unit cost of drainage pipes and filters $(\$ / \mathrm{m}), C_{m}$ is the unit cost of manholes per depth $(\$ / \mathrm{m})$, and $n_{m}$ is the total number of manholes $(-)$, which can be determined by

$$
n_{m}=\frac{A_{\text {tot }}}{E * S}
$$

where $A_{\text {tot }}$ is the total area of the study area $\left(\mathrm{m}^{2}\right), E$ is pipe spacing for subsurface pipe drainage network $(\mathrm{m})$, and $S$ is the distance between manholes along the drainage pipe $(\mathrm{m})$.

The cross-sectional area of excavation $\left(A_{\text {cut }}\right)$ is a trapezoid section as shown in Figure 1 and it can be calculated by

$$
A_{\text {cut }}=\left(b+h_{\text {cut }} * \tan \varnothing\right) * h_{\text {cut }} \text {, }
$$

where $b$ is the bottom width of excavation, $h_{\text {cut }}$ is the total depth of excavation, and $\varnothing$ is the lateral slop angle.

Also, total length of all drainage pipes $\left(\sum l_{i}\right)$ can be replaced by

$$
\sum l_{i}=n_{i} * \bar{l}
$$

where $\bar{l}$ is the mean length of all lateral drainage pipes (m) and $n_{i}$ is the total number of drainage pipes (-), and it can be determined by using the following equation:

$$
n_{i}=\frac{A_{\text {tot }}}{\overline{A_{i}}}
$$

where $\overline{A_{i}}$ is the mean area served by drainage pipes $\left(\mathrm{m}^{2}\right)$, and it can also be determined by using the following equation:

$$
\overline{A_{i}}=E * \bar{l} \text {. }
$$

So, the construction costs can be written as

$$
W_{i}=\frac{A_{\mathrm{tot}}}{E * \bar{l}} * \bar{l} *\left(\left(\left(b+h_{\mathrm{cut}} * \tan \varnothing\right) * h_{\mathrm{cut}}\right) * C_{\mathrm{cut}}+0.5 * I C_{\mathrm{cut}} *\left(\left(b+h_{\mathrm{cut}} * \tan \varnothing\right) * h_{\mathrm{cut}}\right) * h_{\mathrm{cut}}+C_{p}\right)+\frac{A_{\mathrm{tot}}}{E * S} * h_{\mathrm{cut}} * c_{m}
$$


Moreover, the annual investment costs are

$$
U_{i}=P W_{i}+U_{i}^{t},
$$

where $P$ is the rate of depreciation, and it is taken as $15-16$ years. $U_{i}^{t}$ is annual cost of maintenance and service for the drainage network (\$). And it can be calculated by using the following relationship:

$$
U_{i}^{t}=n_{m} * C_{s},
$$

where $C_{\mathrm{s}}$ is the annual cost of maintenance and service for each manhole $(\$)$.

The objective is to design the least-cost pipe drainage network. Thus, the objective function can be stated as

$$
\begin{aligned}
Z_{i}= & \left(1+\frac{\left(1+E_{0}\right)^{D}-1}{E_{0}\left(1+E_{0}\right)^{D}} * P\right)\left[\frac{A_{\mathrm{tot}}}{E} *\left(\left(\left(b+h_{\mathrm{cut}} * \tan \varnothing\right) * h_{\mathrm{cut}}\right) * C_{\mathrm{cut}}+0.5 * I C_{\mathrm{cut}} *\left(\left(b+h_{\mathrm{cut}} * \tan \varnothing\right) * h_{\mathrm{cut}}\right) * h_{\mathrm{cut}}+C_{p}\right)\right. \\
& \left.+\frac{A_{\mathrm{tot}}}{E * S} * h_{\mathrm{cut}} * c_{m}\right]+\frac{\left(1+E_{0}\right)^{D}-1}{E_{0}\left(1+E_{0}\right)^{D}} * \frac{A_{\mathrm{tot}}}{E * S} * C_{s} .
\end{aligned}
$$

\section{Well Drainage Costs}

It is recommended to establish a proper strategy for vertical drainage system design, and it should be connected with the economic factors. For example, we can choose large numbers of tubewells with a small amount of discharge and a slight decrease in the groundwater level from each tubewell, or we can choose small numbers of tubewells with a larger amount of discharge and a larger decrease in the groundwater level from each tubewell and a larger spacing between the tubewells. There are a lot of choices, and these choices are controlled by
(a) Tubewell depth
(b) Tubewell spacing
(c) Tubewell discharge
(d) The decrease amount of the groundwater level

And the most suitable choice can be determined according to the total costs as stated in (1).

The construction costs for vertical drainage project are calculated by using the following equation:

$$
W_{i}=n_{i} * l_{H} * C_{1},
$$

where $n_{i}$ is the total number of tubewells, $l_{H}$ is the total depth of the tubewell $(\mathrm{m})$, and $C_{1}$ is the construction cost of each tubewell per one meter depth $(\$ / \mathrm{m})$.

Moreover, the annual investment costs are

$$
U_{i}=P W_{i}+U_{i}^{t}+U_{i}^{N}
$$

where $U_{i}^{t}$ is the annual cost of maintenance and service for the tubewells (\$). And it can be calculated by using the following relationship:

$$
U_{i}^{t}=n_{i} * C_{2},
$$

where $C_{2}$ is the annual cost of maintenance and service for each tubewell (\$) and $U_{i}^{N}$ is annual cost of electricity for the withdrawal of water from each well (\$). And it is given by

$$
U_{i}^{N}=\frac{9.81}{3600 \eta_{0}} Q_{i} * h_{i} * t * C_{3},
$$

where $Q_{i}$ is the discharge from each tubewell ( $\mathrm{m}^{3} /$ day), $h_{i}$ is the pumping depth $(\mathrm{m}), t$ is the pumps operating hours in the year (day), $C_{3}$ is the cost of kilowatt hours of electricity (\$/kw.h), and $\eta_{0}$ is the pump efficiency (-).

So, the objective function for the design of vertical drainage tubewells can be stated as

$$
z_{i}=n_{i}\left[\left(1+\frac{\left(1+E_{0}\right)^{D}-1}{E_{0}\left(1+E_{0}\right)^{D}} * P\right) * l_{H} * C_{1}+\left(\frac{\left(1+E_{0}\right)^{D}-1}{E_{0}\left(1+E_{0}\right)^{D}}\right) *\left(C_{2}+\frac{9.81}{3600 \eta_{0}} * Q_{i} * h_{i} * t * C_{3}\right)\right]
$$

\section{Case Study}

5.1. Case Study Description. A total area of 500 hectares is attended to apply an irrigation network to meet the crops need and help in washing the salinity that comes from underground water. So, a drainage network is needed also along with the irrigation network to serve in releasing exceed salty water out of the study area. The study area is located in Syria, as shown in Figure 2. The net area of cultivation is 405 hectares. About $15 \%$ of the net area is covered by summer vegetables, and wheat occupies the largest proportion among the crops list 


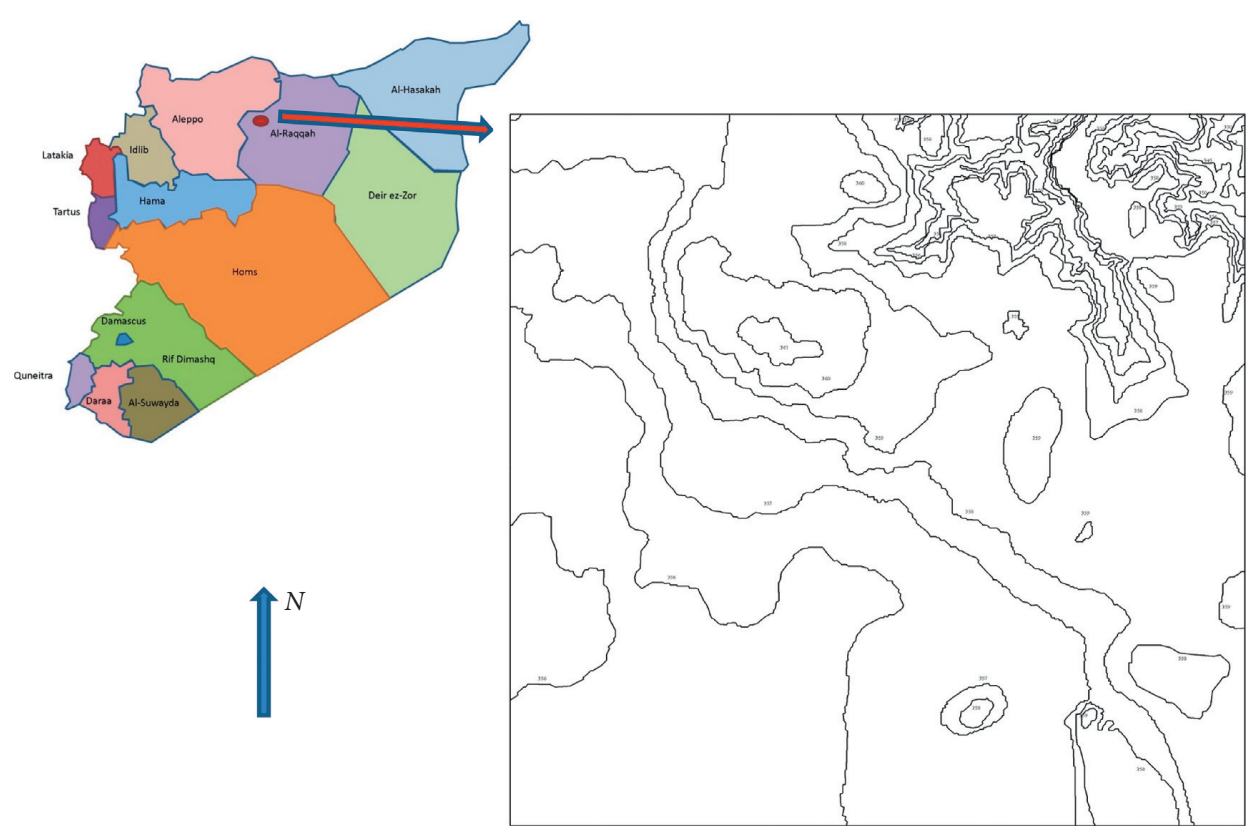

Figure 2: The location and topography of the study area.

which is about $44.3 \%$, followed by cotton (35\%) and barley $(12.7 \%)$.

Table 1 gives the general climate and crops indicators for the region.

The study area contains three different soil layers ( $h_{1}=7 \mathrm{~m}, h_{2}=12 \mathrm{~m}$, and $h_{3}=15 \mathrm{~m}$ ) with different hydraulic conductivity $\left(k_{1}=0.8 \mathrm{~m} /\right.$ day, $k_{2}=3.2 \mathrm{~m} /$ day, and $k_{3}=11.2 \mathrm{~m} /$ day), and there is a semi-impermeable layer under the third layer with thickness of $h_{4}=2 \mathrm{~m}$ and hydraulic conductivity of $k_{4}=0.01 \mathrm{~m} /$ day, as shown in Figure 3.

The groundwater table is about $3 \mathrm{~m}$ below the ground surface, the gradient of the groundwater surface at the beginning of the study area is $J_{1}=0.006$, and the gradient of the groundwater surface at the end of the study area is $J_{2}=0.001$. The general gradient of the study area is from north to the south, so the length of groundwater feeding line is $L=2430 \mathrm{~m}$, leakage from irrigation network is $\varphi=6820.789 \mathrm{~m}^{3} / \mathrm{ha} /$ year, and the increasing amount of irrigation discharge to avoid salinity problems is $g=627.276 \mathrm{~m}^{3} /$ ha/year.

Unit cost of excavation is $C_{\text {cut }}=50\left(\mathrm{RMB} / \mathrm{m}^{3}\right)$, increase in unit cost of earthwork per unit depth of excavation is $I C_{\text {cut }}=3\left(\mathrm{RMB} / \mathrm{m}^{3} / \mathrm{m}\right)$, unit cost of drainage pipes and filters is $C_{\mathrm{p}}=10(\mathrm{RMB} / \mathrm{m})$, unit cost of manholes per depth is $C_{\mathrm{m}}=200(\mathrm{RMB} / \mathrm{m})$, annual cost of maintenance and service for each manhole is $C_{s}=10(\mathrm{RMB}), \varnothing=0.78$, and distance between manholes along the drainage pipe is $S=100 \mathrm{~m}$. Construction cost of each tubewell per one meter depth is $C_{1}=860(\mathrm{RMB} / \mathrm{m})$, annual cost of maintenance and service for each tubewell is $C_{2}=80$ ( $\mathrm{RMB} /$ year), the cost of kilowatt hours of electricity is $C_{3}=0.52(\mathrm{RMB} / \mathrm{kw} \cdot \mathrm{h})$, pump efficiency is $\eta_{0}=0.78$, specific given factor is $\mu=0.06$, rate of depreciation is $P=1 / 15$, and interest rate is $E_{0}=8 \%$. The drainage depth is $m=1 \mathrm{~m}$.
5.2. Pipe Drainage Spacing Formulation. We can determine the pipe spacing for subsurface pipe drainage network when we have three different layers and the permeability is increasing with depth by using the following formulations [22]:

$$
E=4\left(\sqrt{f^{2}+T \frac{H}{2 q_{c}}}-f\right)
$$

where

$$
\begin{aligned}
& T=\sum\left(K_{i} h_{i}\right), \\
& f=\beta_{1} \beta_{2} h\left(\frac{K_{3}}{K_{1}}\right) \sigma+\beta_{t} h_{t}\left\{\frac{\left(K_{2}-K_{3}\right)}{K_{1}}\right\} \sigma_{t}+\left\{\frac{\left(K_{1}-K_{2}\right)}{K_{1}}\right\} \sigma_{1} h_{1}^{*} .
\end{aligned}
$$

As $\sigma, \sigma_{1}$, and $\sigma_{t}$ can be calculated by using the following formulations:

$$
\begin{aligned}
\sigma & =0.366 \log \frac{h}{2 \pi r \sin ((H+r) / 2 h)}, \\
\sigma_{1} & =0.366 \log \frac{h_{1}^{*}}{2 \pi r \sin \left((H+r) / 2 h_{1}^{*}\right)}, \\
\sigma_{t} & =0.366 \log \frac{h_{t}}{2 \pi r \sin \left((H+r) / 2 h_{t}\right)},
\end{aligned}
$$

where $H$ is the hydraulic head (m), which is the water table height above the drainage pipe at the midpoint between the drainage pipes as seen in Figure $4, T$ is the weighted transmissivity for all layers contributing to the flow $\left(\mathrm{m}^{2} /\right.$ day), $q_{c}$ is the drainage unit discharge that must be released by drainage pipes (m/day), $K_{i}$ is the hydraulic conductivity for each layer (m/day), $h_{i}$ is the thickness of each saturated 
TAвLE 1: General climate and crops indicators for the study area.

\begin{tabular}{|c|c|c|c|c|c|c|c|c|c|c|c|c|c|c|}
\hline Factor & Month & 1 & 2 & 3 & 4 & 5 & 6 & 7 & 8 & 9 & 10 & 11 & 12 & $\begin{array}{l}\text { The average } \\
\text { annual }\end{array}$ \\
\hline \multicolumn{2}{|l|}{ Temperature } & 7.3 & 9.1 & 12.5 & 16.4 & 21 & 25.9 & 27.9 & 28.1 & 24.5 & 19.1 & 13.4 & 8.6 & 17.8 \\
\hline \multirow{2}{*}{ Rainfall (mm) } & $\%$ & 18.7 & 14.1 & 13.3 & 8.6 & 3.2 & 0.7 & 0 & 0.2 & 1.6 & 8.6 & 8.5 & 22.2 & 99.7 \\
\hline & Monthly rate & 121 & 91.6 & 84.9 & 55.9 & 21.2 & 4.8 & 0 & 1.9 & 10.6 & 54.9 & 54.9 & 145.6 & 649 \\
\hline \multirow{2}{*}{$\begin{array}{l}\text { Evaporation from free } \\
\text { water surface }(\mathrm{mm} / \text { day })\end{array}$} & Lambert & 1.2 & 1.7 & 2.4 & 2.6 & 5.7 & 7.9 & 10.5 & 9.5 & 6.5 & 3.8 & 1.4 & 1.1 & 4.8 \\
\hline & Ivanov & 1.1 & 1.6 & 2.5 & 3.9 & 5.6 & 8.4 & 9.3 & 8.7 & 7.3 & 4.5 & 2.5 & 1.2 & 4.7 \\
\hline \multicolumn{2}{|c|}{ Evatranspiration $(\mathrm{mm} /$ day $)$} & 0.7 & 1.8 & 2.5 & 4.4 & 6.6 & 8.4 & 8.9 & 8.9 & 6.1 & 3.2 & 2 & 0.7 & 4.56 \\
\hline \multirow{3}{*}{ Crop needs (mm/month) } & $\begin{array}{l}\text { Wheat and } \\
\text { barley }\end{array}$ & 15.19 & 35.28 & 54.25 & 92.4 & 0 & 0 & 0 & 0 & 0 & 0 & 42 & 15.19 & 21.25 \\
\hline & Cotton & 0 & 35.28 & 54.25 & 92.4 & 143.22 & 176.4 & 193.13 & 193.13 & 0 & 0 & 0 & 0 & 73.98 \\
\hline & $\begin{array}{l}\text { Summer } \\
\text { vegetables }\end{array}$ & 0 & 35.28 & 54.25 & 92.4 & 143.22 & 176.4 & 193.13 & 0 & 0 & 0 & 0 & 0 & 57.89 \\
\hline
\end{tabular}

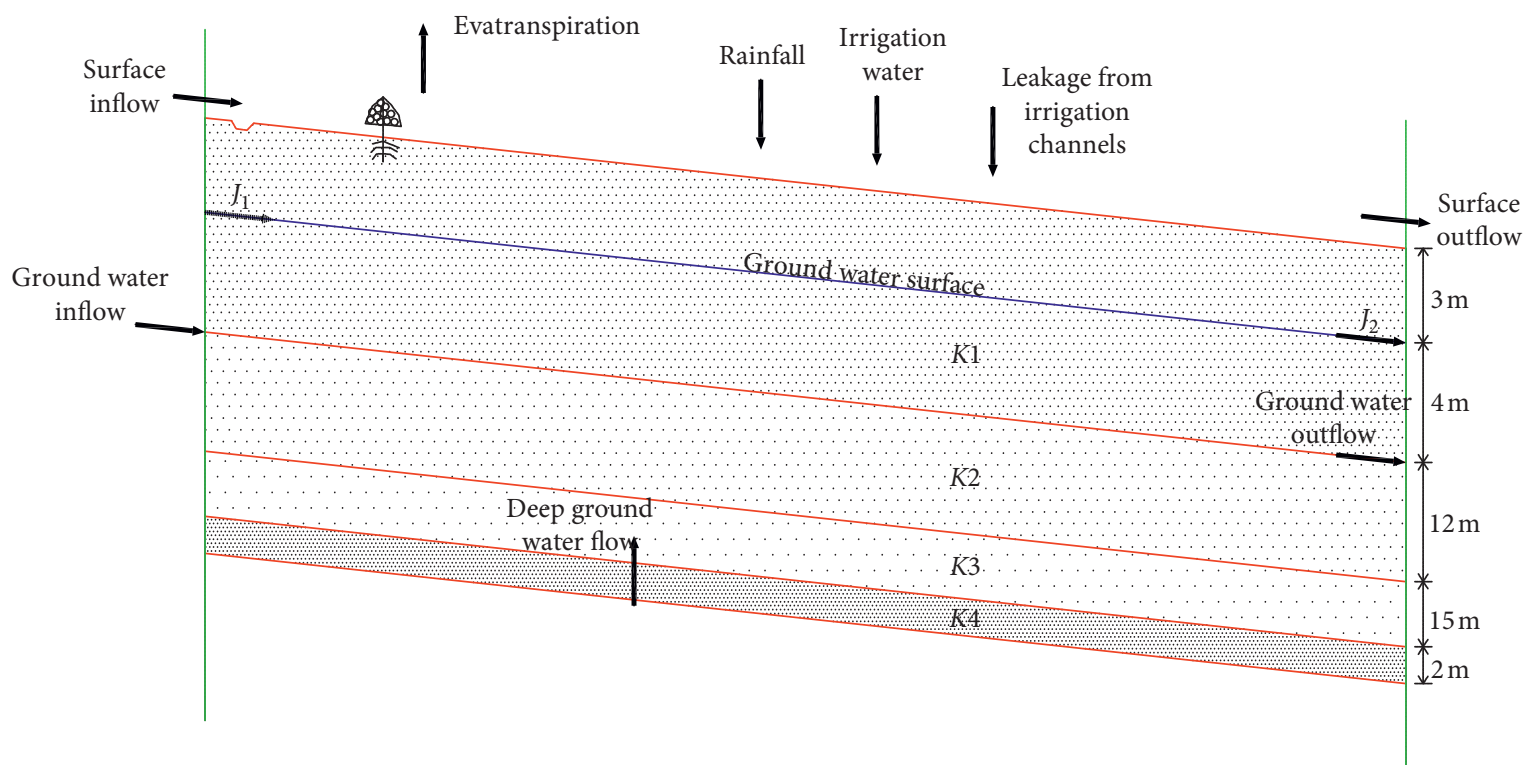

FIgURE 3: Hydrogeology of the study area.

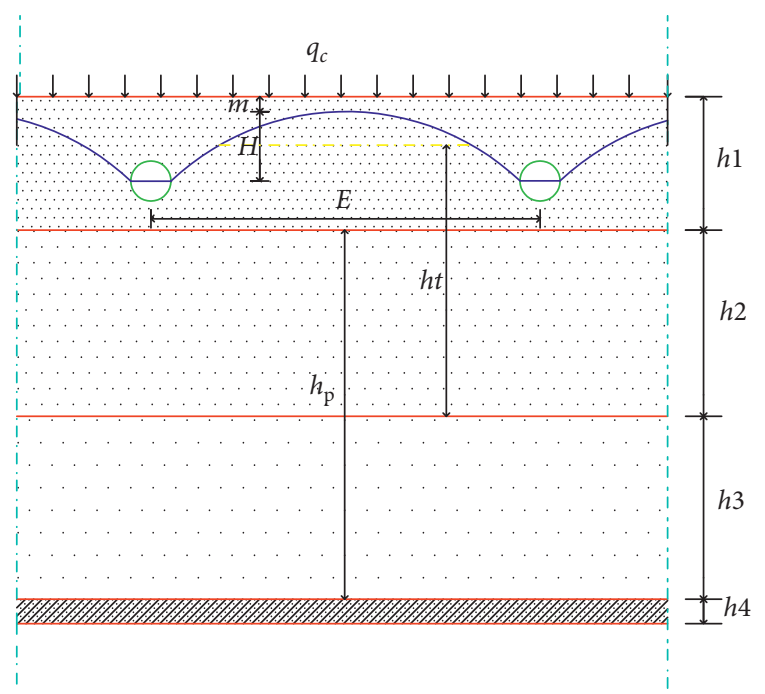

Figure 4: Case study pipe drainage geometry. layer $(\mathrm{m}), h$ is the thickness of all saturated layers $(\mathrm{m}), r$ is the radius of drainage pipe $(\mathrm{m})$, and $h_{1}^{*}$ and $h_{t}(\mathrm{~m})$ can be defined as

$$
\begin{aligned}
& h_{1}^{*}=h_{1}-m-\frac{H}{2}, \\
& h_{t}=h_{1}^{*}+h_{2},
\end{aligned}
$$

where $m$ is the drainage depth $(\mathrm{m})$, which is the minimum depth required by each plant for better productivity.

And we can obtain $\beta_{1}, \beta_{2}$, and $\beta_{t}$ values from Figure 5, after calculating the factors $\psi, \lambda$, and $\varepsilon$ as seen in Table 2 .

The drainage unit discharge $\left(q_{c}\right)$ that must be released by drainage pipes can be obtained by studying the water balance in the study area.

5.3. Hydraulic Study of Drainage Pipes. For the hydraulic study of subsurface drainage pipes, we can use Manning formula which is as follows: 


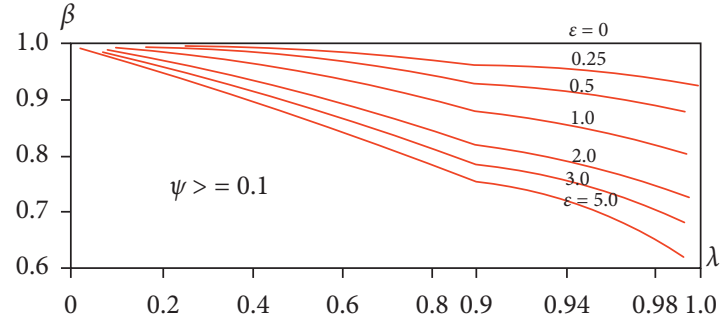

(a)

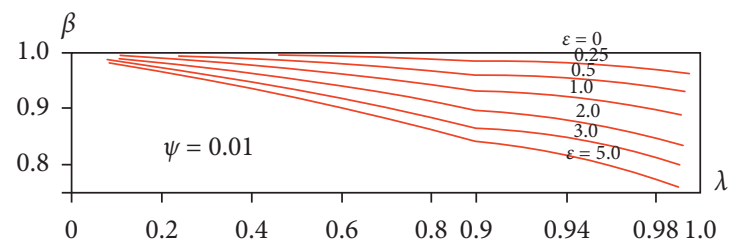

(b)

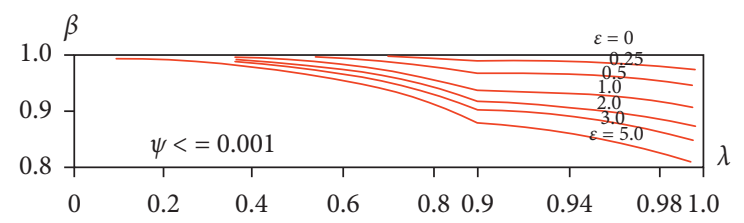

(c)

Figure 5: Determination of $\beta p, \beta_{3}$, and $\beta_{4}$ values [22].

TABle 2: Calculation of $\psi, \lambda$, and $\varepsilon$ factors for the values of $\beta_{1}, \beta_{2}$, and $\beta_{t}[22]$.

\begin{tabular}{cccc}
\hline & $\beta_{1}$ & $\beta_{2}$ & $\beta_{t}$ \\
\hline$\psi$ & $\left(r / h_{1}^{*}\right)$ & $\left(r / h_{1}^{*}\right)$ & $\left(r / h_{1}^{*}\right)$ \\
$\lambda$ & $\left(k_{3}-k_{2} / k_{3}+k_{2}\right)$ & $\left(k_{2}-k_{1} / k_{2}+k_{1}\right)$ & $\left(k_{2}-k_{1} / k_{2}+k_{1}\right)$ \\
$\varepsilon$ & $\left(h_{3} / h_{t}\right)$ & $\left(h_{p} / h_{1}^{*}\right)$ & $\left(h_{2} / h_{1}^{*}\right)$ \\
\hline
\end{tabular}

$$
Q=\frac{1}{n} * R^{(2 / 3)} * A * \sqrt{I},
$$

where $Q$ is the discharge that must be drained by the drainage pipes $\left(\mathrm{m}^{3} / \mathrm{sec}\right), n$ is the roughness coefficient $(-), R$ is the hydraulic radius ( $\mathrm{m}), A$ is the water cross section area $\left(\mathrm{m}^{2}\right)$, and $I$ is the hydraulic gradient.

For better calculation of drainage pipe diameter, we can consider that the pipe is full of water, but we have to choose a pipe with an actual diameter greater than the calculated one in order to guarantee the free surface flow inside the drainage pipe.

The calculated velocity inside the drainage pipes must be between these limits:

$$
1 \geq V \geq 0.15 \mathrm{~m} / \mathrm{sec}
$$

And the critical pipe diameter must achieve the following formula:

$$
d_{\varphi} \geq d_{\mathrm{cr}}=0.262 * \frac{q^{*}}{K_{m}},
$$

where $d_{\varphi}$ is the drainage ditch width $(\mathrm{m}), d_{\mathrm{cr}}$ is the critical pipe diameter $(\mathrm{m}), K_{m}$ is the weighted hydraulic conductivity for all layers contributing to the flow (m/day), and $q^{*}$ is the drainage unit discharge $\left(\mathrm{m}^{3} / \mathrm{day} / \mathrm{m}\right)$, which can be calculated by using the following equation:

$$
q^{*}=q_{c} * E * 1
$$

5.4. Pipe Drainage Optimization Problem. The optimization problem for the pipe drainage design can be stated as follows.

Minimize

$$
\begin{aligned}
& Z_{i}=\left(1+\frac{\left(1+E_{0}\right)^{D}-1}{E\left(1+E_{0}\right)_{0}^{D}} * P\right) *\left[\frac { A _ { \mathrm { tot } } } { E } * \left(\left(\left(b+h_{\mathrm{cut}} * \tan \varnothing\right) * h_{\mathrm{cut}}\right) * C_{\mathrm{cut}}+0.5 * I C_{\mathrm{cut}} *\left(\left(b+h_{\mathrm{cut}} * \tan \varnothing\right) * h_{\mathrm{cut}}\right)\right.\right. \\
& \left.\left.* h_{\mathrm{cut}}+C_{p}\right)+\frac{A_{\mathrm{tot}}}{E * S} * h_{\mathrm{cut}} * c_{m}\right] \\
& +\frac{\left(1+E_{0}\right)^{D}-1}{E_{0}\left(1+E_{0}\right)^{D}} * \frac{A_{\mathrm{tot}}}{E * S} * C_{s}
\end{aligned}
$$


Subject to

$$
\begin{aligned}
& E=4\left(\sqrt{f^{2}+T \frac{H}{2 q_{c}}}-f\right), \\
& 2 r \geq 0.262 * \frac{q * E}{K_{m}},
\end{aligned}
$$

$\{H, E\}>0$,

in which

$$
\begin{aligned}
f & =\beta_{1} \beta_{2} h\left(\frac{K_{3}}{K_{1}}\right) \sigma+\beta_{t} h_{t}\left\{\frac{\left(K_{2}-K_{3}\right)}{K_{1}}\right\} \sigma_{t}+\left\{\frac{\left(K_{1}-K_{2}\right)}{K_{1}}\right\} \sigma_{1} h_{1}^{*}, \\
\sigma & =0.366 \log \frac{h}{2 \pi r \sin ((2 m+r) / 2 h)}, \\
\sigma_{1} & =0.366 \log \frac{h_{1}^{*}}{2 \pi r \sin \left((2 m+r) / 2 h_{1}^{*}\right)}, \\
\sigma_{t} & =0.366 \log \frac{h_{t}}{2 \pi r \sin \left((2 m+r) / 2 h_{t}\right)} .
\end{aligned}
$$

5.5. Well Drainage Spacing Formulation. According to Soviet Science Encyclopedia for calculating and design of drainage networks and land reclamation, we can determine the tubewells spacing when the permeability is increasing with depth by using the following formulation [22]:

$$
h_{s w}=h_{c}+\frac{q_{c 1} B^{2}}{T}\left(\rho+f_{c}\right) \text {, }
$$

where

$$
\begin{aligned}
H & =h_{s w}-h_{c}, \\
H & =\frac{q_{c 1} B^{2}}{T}\left(\rho+f_{c}\right), \\
\rho & =0.336 \cdot \log \frac{B}{\pi r_{c}}, \\
f_{c} & =\beta_{3} \beta_{4} \frac{k_{1}}{k_{3}} \sigma_{c}+\beta_{p} \frac{k_{2}-k_{1}}{k_{3}} \sigma_{c p}+\frac{k_{3}-k_{2}}{k_{3}} \sigma_{c 3} .
\end{aligned}
$$

When the well is not reaching the impermeable layer $\left(m_{2} \neq 0\right)$, then

$$
\sigma=\frac{1}{2 \pi}\left(\frac{1-x}{x} \ln \frac{0.7 l_{k}}{r_{c}}+\ln \frac{1}{x}+\frac{\Delta \varepsilon}{2}\right),
$$

where

$$
x=\frac{l_{k}}{h_{i}}
$$

For calculating $\sigma_{c}$, we put $\left(h_{i}=h=h_{1}^{*}+h_{2}+h_{3}\right)$, for calculating $\sigma_{\mathrm{cp}}$, we put $\left(h_{i}=h_{p}=h_{2}+h_{3}\right)$, and for calculating $\sigma_{c 3}$, we put $\left(h_{i}=h_{3}\right)$, as described in Figure 6 .

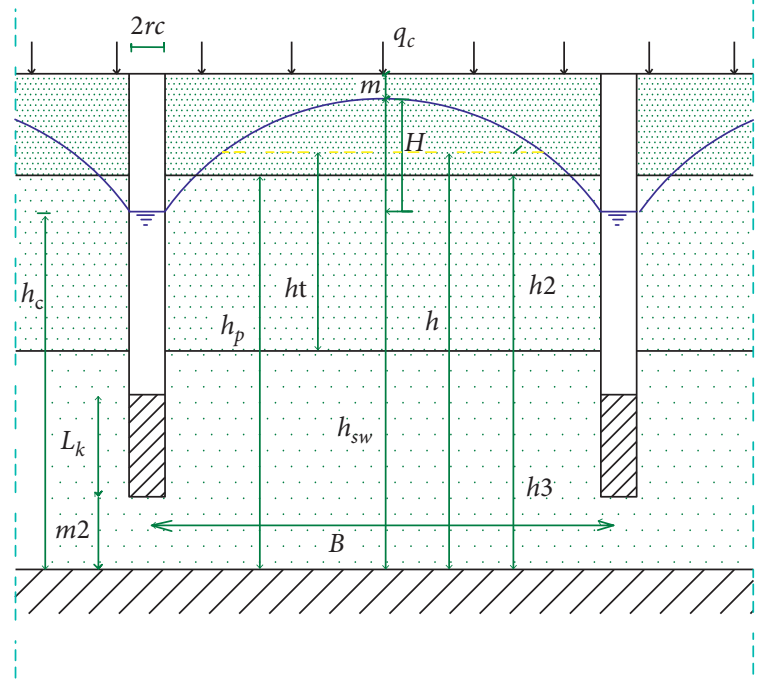

Figure 6: Case study vertical drainage geometry.

TABLE 3: $\Delta_{\varepsilon}$ values according to the value $\left(m+\left(L_{k} / 2\right)\right) / h_{i}[22]$.

\begin{tabular}{lccccccc}
\hline$\left(\mathbf{m}+\left(\mathbf{L}_{\mathbf{k}} / 2\right)\right) / \mathbf{h}_{\mathbf{i}}$ & 0.1 & 0.15 & 0.2 & 0.25 & 0.3 & 0.4 & 0.5 \\
\hline$\Delta_{\varepsilon}$ & 2.33 & 1.07 & 0.49 & 0.17 & -0.01 & -0.19 & -0.22 \\
\hline
\end{tabular}

TABLE 4: Calculation of $\psi, \lambda$, and $\varepsilon$ factors for the values of $\beta_{3}, \beta_{4}$, and $\beta_{p}[22]$.

\begin{tabular}{lccc}
\hline & $\beta_{3}$ & $\beta_{4}$ & $\beta_{p}$ \\
\hline$\Psi$ & $\left(r / h_{1}^{*}\right)$ & $\left(r / h_{1}^{*}\right)$ & $\left(r / h_{1}^{*}\right)$ \\
$\Lambda$ & $\left(k_{2}-k_{1} / k_{1}+k_{2}\right)$ & $\left(k_{3}-k_{2} / k_{2}+k_{3}\right)$ & $\left(k_{3}-k_{2} / k_{2}+k_{3}\right)$ \\
$\mathrm{E}$ & $\left(h_{1}^{*} / h_{p}\right)$ & $\left(h_{t} / h_{3}\right)$ & $\left(h_{2} / h_{3}\right)$ \\
\hline
\end{tabular}

We can obtain the $\Delta_{\varepsilon}$ values from Table 3 .

And we can obtain $\beta_{p}, \beta_{3}$, and $\beta_{4}$ values from Figure 5, after calculating the factors $\lambda, \psi$, and $\varepsilon$ as seen in Table 4 .

In Table $4, r_{c}$ is the radius of vertical well $(\mathrm{m}), L_{k}$ is the length of the filter $(\mathrm{m}), B$ is the spacing between vertical wells $(\mathrm{m}), h_{s w}$ is the maximum thickness of saturated layers $(\mathrm{m}), h_{c}$ is the water depth inside the tubewell above the impermeable layer $(\mathrm{m})$, and $q_{c 1}$ is the drainage unit discharge that must be released by investment wells, and it can be calculated by using the following formula:

$$
\begin{aligned}
& q_{c 1}=p_{1}+p_{2}, \\
& p_{1}=\varphi+g, \\
& p_{2}=10^{4} k_{4} \frac{\Delta h}{h_{4}} t, \\
& \Delta h=\frac{p_{1}}{k_{1}}\left(h_{1}-m\right),
\end{aligned}
$$

where $p_{1}$ is the discharge that comes from surface water $(\mathrm{m} /$ day), $p_{2}$ is the discharge that comes from groundwater $(\mathrm{m} /$ day), $\varphi$ is the leakage from irrigation network ( $\mathrm{m} /$ day), and $g$ is the increasing amount of irrigation discharge to avoid salinity problems (m/day). 
5.6. Surrounding Wells Spacing Formula. Protection vertical wells are placed at the edge of the study area along the feeding line $L$, to protect the study area from the upcoming groundwater along the feeding line. This means that these wells will act as an investment and protection role; the deep groundwater component coming to the study area through the fixed-length $L$ and for a slide of $1 \mathrm{~m}$ width is given by the following relationship:

$$
\begin{aligned}
G & =k_{m} h\left(J_{1}-J_{2}\right), \\
k_{m} & =\frac{\sum k_{i} \cdot h_{i}}{h},
\end{aligned}
$$

where $G$ is the groundwater component $\left(\mathrm{m}^{3} / \mathrm{m} /\right.$ day $)$ that gathers in the study area during the day, $J_{1}$ is the gradient of the groundwater surface at the beginning of the study area $(-)$, and $J_{2}$ is the gradient of the groundwater surface at the end of the study area (-).

The spacing between surrounding wells can be calculated by using the following formula:

$$
B^{\text {or }}=\sqrt{\frac{G^{2}}{4 q_{c 1}^{2}}+B^{2}}-\frac{G}{2 q_{c 1}} .
$$

5.7. Determining the Number of Drainage Wells. The total discharge that has to be released by all drainage wells can be determined by

$$
Q_{\mathrm{tot}}=G_{y r} * l+q_{c 1} * F .
$$

The discharge of each drainage well is

$$
Q_{i}=q_{c 1} * B^{2} .
$$

Thus, the total number of drainage wells is

$$
n=\frac{Q_{\text {tot }}}{Q_{i}} .
$$

The number of surrounding wells can be obtained by

$$
n_{\text {or }}=\frac{L}{B^{\text {or }}} \text {. }
$$

Thus, the number of investment wells is

$$
n_{i}=n-n_{\mathrm{or}}
$$

5.8. Pump Operating Hours. The duration of pump operating required to maintain a favourable drainage depth is given by

$$
t_{H c}=\frac{\mu \pi R^{2} H}{2 Q_{i}},
$$

where $\mu$ is a specific given factor $(-)$ and $R$ is the radius of influence of the wells, and it can be calculated according to the distribution of the wells as follows.

(i) If the tubewells are placed in a rectangular pattern, $R=0.565 * B$

(ii) If the tubewells are placed in a triangular pattern, $R=0.526 * B$

In our study, we will choose a rectangular pattern. Some researchers suggest operating the pumps only during the weeding period, but others prefer to operate the pumps in certain hours every day.

5.9. Well Drainage Optimization Problem. The optimization problem for the well drainage design can be stated as follows.

Minimize

$$
\begin{aligned}
Z_{i}= & Q_{\text {tot }}\left[\frac{\left(1+\left(\left(1+E_{0}\right)^{D}-1 / E_{0}\left(1+E_{0}\right)^{D}\right) * P\right) * l_{H} * C_{1}+\left(\left(1+E_{0}\right)^{D}-1 / E_{0}\left(1+E_{0}\right)^{D}\right) * C_{2}}{q_{c 1} * B^{2}}\right. \\
& \left.+\frac{\left(1+E_{0}\right)^{D}-1}{E_{0}\left(1+E_{0}\right)^{D}} * \frac{9.81}{3600 \eta_{0}} *(H+m) * t * C_{3}\right] .
\end{aligned}
$$

Subject to

$$
\begin{aligned}
H & =\frac{q_{c 1} * B^{2}}{T}\left(0.336 \log \frac{B}{\pi r_{c}}+f_{c}\right), \\
t & =\frac{\mu \pi 0.565^{2} H}{2 q_{c 1}} .
\end{aligned}
$$

\section{Results and Discussion}

Table 5 shows the general parameters calculated for both pipe and well drainage design.
By applying these values on the computer code in MATLAB environment, we derived the optimal solution for the pipe drainage design for a range of lifespan as seen in Table 6.

And the optimal solution for the vertical drainage design for a range of lifespan is shown in Table 7.

As we can see, for horizontal and vertical drainage networks, it is better to choose large distance between the lateral pipes and wells. These distances can be calculated by applying the optimization model on the study area. And for the case study described above, the vertical drainage will be a better solution as subsurface drainage design for the whole 
TABLE 5: General parameters calculated for the design of pipe and well drainage.

\begin{tabular}{|c|c|c|c|c|c|c|c|c|c|}
\hline Parameter & $q_{c 1}(\mathrm{~m} /$ day $)$ & $q_{c}(\mathrm{~m} /$ day $)$ & $Q_{\text {tot }}\left(\mathrm{m}^{3} /\right.$ day $)$ & $\beta_{1} / \beta_{3}$ & $\beta_{2} / \beta_{4}$ & $\beta_{t} / \beta_{p}$ & $\Delta_{\varepsilon 1}$ & $\Delta_{\varepsilon 2}$ & $\Delta_{\varepsilon 3}$ \\
\hline Pipe drainage & $2.861 * 10^{-3}$ & $3.333 * 10^{-3}$ & 16665 & 0.95 & 0.9 & 0.92 & & & \\
\hline Well drainage & $2.861 * 10^{-3}$ & $3.333 * 10^{-3}$ & 16665 & 1 & 0.95 & 0.95 & 0.911818 & 0.87667 & -0.01 \\
\hline
\end{tabular}

TABle 6: Pipe drainage optimal solution for a range of lifespan.

\begin{tabular}{lccc}
\hline Lifespan $D$ (years) & Pipe spacing $E(\mathrm{~m})$ & Hydraulic head $H(\mathrm{~m})$ & Total cost $Z(\mathrm{RMB})$ \\
\hline 1 & 234.4577 & 1.3189 & $8.5823 e+06$ \\
10 & 234.8422 & 1.3211 & $1.1711 e+07$ \\
50 & 235.0565 & 1.3223 & $1.4698 e+07$ \\
100 & 235.0644 & 1.3223 & $1.4840 e+07$ \\
\hline
\end{tabular}

TABLE 7: Well drainage optimal solution for a range of lifespan.

\begin{tabular}{|c|c|c|c|c|c|c|c|c|c|}
\hline $\begin{array}{l}\text { Lifespan } \\
D \text { (years) }\end{array}$ & $\begin{array}{l}\text { Hydraulic } \\
\text { head } H(\mathrm{~m})\end{array}$ & $\begin{array}{l}\text { Duration of } \\
\text { pumping } \\
\text { operation } t \\
\text { (days) }\end{array}$ & $\begin{array}{c}\text { Well } \\
\text { spacing } B \\
\text { (m) }\end{array}$ & $\begin{array}{l}\text { Total cost } Z \\
\quad(\mathrm{RMB})\end{array}$ & $\begin{array}{c}\text { The } \\
\text { discharge of } \\
\text { each well } Q_{i} \\
\left(\mathrm{~m}^{3} / \text { day }\right)\end{array}$ & $\begin{array}{c}\text { Total } \\
\text { number } \\
\text { of wells } n\end{array}$ & $\begin{array}{c}\text { Surrounding } \\
\text { wells spacing } \\
B_{\text {or }}(\mathrm{m})\end{array}$ & $\begin{array}{l}\text { Number of } \\
\text { surrounding } \\
\text { wells } n_{\text {or }}\end{array}$ & $\begin{array}{c}\text { Number of } \\
\text { investment } \\
\text { wells } n_{i}\end{array}$ \\
\hline 1 & 17.5848 & 184.9211 & 881.0597 & $2.9559 e+05$ & 2220.8976 & 7.5 & 716.7423 & 3.4 & 4.1 \\
\hline 10 & 9.9645 & 104.7862 & 673.7206 & $7.0352 e+05$ & 1298.6063 & 12.8 & 515.0194 & 4.7 & 8.1 \\
\hline 50 & 8.7810 & 92.3413 & 634.5266 & $1.0038 e+06$ & 1151.9073 & 14.5 & 477.2781 & 5.1 & 9.4 \\
\hline 100 & 8.7468 & 91.9817 & 633.3536 & $1.0174 e+06$ & 1147.6523 & 14.5 & 476.1512 & 5.1 & 9.4 \\
\hline
\end{tabular}

project lifespan. The cost for operating vertical drainage pumps plays an important role in determining the optimal design when considering the lifespan of the project.

\section{Conclusions}

In order to formulate an optimization problem for the design of subsurface drainage systems, cost equations have been introduced for both horizontal and vertical drainage. The cost equations contained the most cost components that affect the subsurface drainage networks design. Then the optimization problem constraints were derived from the hydraulic study of the case study. The case study contains three different soil layers with different hydraulic conductivity and permeability, and the permeability is increasing with depth. A mathematical model was formulated for the horizontal and vertical drainage optimal design in the case study. The result was a nonlinear optimization problem with nonlinear constraints, which required numerical methods for its solution. A survey of modern optimization algorisms was conducted to find the one suitable for the solution of the formulated problem. It was found that the interior-point optimization algorithm was adapted to the problem and produced satisfactory results. The results show that the proposed optimal mathematical model for both horizontal and vertical drainage networks was affected mostly by the distance between pipes and wells, and the optimal solution involved the maximum possible values of pipes and tubewells spacing. Also, for this case study, the model gave a lower cost for the designing of tubewells network compared with pipe network. And the total cost for the vertical drainage design involved minimum duration of pump operation when considering the lifespan of the subsurface drainage project. The study has shown that the pipes and tubewells spacing and the groundwater table drawdown cannot be selected randomly if we put the economic factor in consideration. Traditional pipes and tubewells design may lead to high costs compared with the optimal design. It is hoped that the proposed optimal mathematical model will present a design methodology by which the costs of all alternative designs can be compared so that the least-cost design is selected.

\section{Data Availability}

The data that support the findings of this study are available from the corresponding author upon reasonable request.

\section{Conflicts of Interest}

The authors declare no conflicts of interest.

\section{Acknowledgments}

The authors would like to thank Hohai University for granting the scholarship which made the research possible; lab mates, Genxiang Feng and Wang Ce, for their suggestions and help; friends, Wael Alhasan and Saeed Assani, for their big support and help. This research was funded by the National Natural Science Foundation of China, under grant number 51879071.

\section{References}

[1] C. D. Kennedy, C. Bataille, Z. Liu et al., "Dynamics of nitrate and chloride during storm events in agricultural catchments with different subsurface drainage intensity (Indiana, USA)," Journal of Hydrology, vol. 466-467, pp. 1-10, 2012. 
[2] C. Xian, Z. Qi, C. S. Tan, and T.-Q. Zhang, "Modeling hourly subsurface drainage using steady-state and transient methods," Journal of Hydrology, vol. 550, pp. 516-526, 2017.

[3] M. Akram, A. Azari, A. Nahvi, Z. Bakhtiari, and H. D. Safaee, "Subsurface drainage in Khuzestan, Iran: environmentally revisited criteria," Irrigation and Drainage, vol. 62, no. 3, pp. 306-314, 2013.

[4] S. I. Yannopoulos, M. E. Grismer, K. M. Bali, and A. N. Angelakis, "Evolution of the materials and methods used for subsurface drainage of agricultural lands from antiquity to the present," Water, vol. 12, no. 6, p. 1767, 2020.

[5] H. S. Acharya and D. G. Holsambre, "Optimum depth and spacing of subsurface drains," Journal of the Irrigation and Drainage Division, vol. 108, no. 1, pp. 77-80, 1982.

[6] A. K. Bhattacharya, N. Faroud, S.-T. Chieng, and R. S. Broughton, "Subsurface drainage cost and hydrologic model," Journal of the Irrigation and Drainage Division, vol. 103, no. 3, pp. 299-308, 1977.

[7] J. Boumans and L. Smedema, "Derivation of cost-minimizing depth for lateral pipe drains," Agricultural Water Management, vol. 12, no. 1-2, pp. 41-51, 1986.

[8] B. R. Chahar and G. P. Vadodaria, "Optimal spacing in an array of fully penetrating ditches for subsurface drainage," Journal of Irrigation and Drainage Engineering, vol. 136, no. 1, pp. 63-67, 2010.

[9] D. S. Durnford, T. H. Podmore, and E. V. Richardson, "Optimal drain design for arid, irrigated areas," Transactions of the ASAE, vol. 27, no. 4, pp. 1100-1105, 1984.

[10] H. Ritzema, H. Nijland, and F. Croon, "Subsurface drainage practices: from manual installation to large-scale implementation," Agricultural Water Management, vol. 86, no. 1-2, pp. 60-71, 2006.

[11] E. H. Wiser, R. C. Ward, and D. A. Link, "Optimized design of a subsurface drainage system," Transactions of the ASAE, vol. 17, no. 1, pp. 175-0178, 1974.

[12] L. Cimorelli, L. Cozzolino, C. Covelli, C. Mucherino, A. Palumbo, and D. Pianese, "Optimal design of rural drainage networks," Journal of Irrigation and Drainage Engineering, vol. 139, no. 2, pp. 137-144, 2013.

[13] M. Moradi-Jalal, M. A. Mariño, and A. Afshar, "Optimal design and operation of irrigation pumping stations," Journal of Irrigation and Drainage Engineering, vol. 129, no. 3, pp. 149-154, 2003.

[14] M. Moradi-Jalal, S. I. Rodin, and M. A. Mariño, "Use of genetic algorithm in optimization of irrigation pumping stations," Journal of Irrigation and Drainage Engineering, vol. 130, no. 5, pp. 357-365, 2004.

[15] A. K. Sharma and P. K. Swamee, "Cost considerations and general principles in the optimal design of water distribution systems," in Proceedings of the Water Distribution Systems Analysis Symposium, Cincinnati, OH, USA, August 2006.

[16] M. S. Bennett and L. W. Mays, "Optimal design of detention and drainage channel systems," Journal of Water Resources Planning and Management, vol. 111, no. 1, pp. 99-112, 1985.

[17] B. H. Wall and A. J. Miller, "Optimization of parameters in a model of soil water drainage," Water Resources Research, vol. 19, no. 6, pp. 1565-1572, 1983.

[18] A. D. Howard, "Theoretical model of optimal drainage networks," Water Resources Research, vol. 26, no. 9, pp. 2107-2117, 1990.

[19] L. Stuyt, W. Dierickx, and J. M. Beltrán, Materials for Subsurface Land Drainage Systems, Food \& Agriculture Organization, Rome, Italy, 2005.
[20] H. Nijland, F. W. Croon, and H. P. Ritzema, Subsurface Drainage Practices: Guidelines for the Implementation, Operation and Maintenance of Subsurface Pipe Drainage Systems, ILRI, Nairobi, Kenya, 2005.

[21] R. Broughton and J. Fouss, "Subsurface drainage installation machinery and methods," Agricultural Drainage, vol. 38, pp. 963-1003, 1999.

[22] G. N. Ganicheva, "Special works in municipal reclamation and water management," in Departmental Norms and Prices on Installation, Repair and Construction Works, E. M. Bespalova, Ed., Preiskurantizdat, Moscow, Russia, 1987. 